\title{
Entre a manutenção da tradição bandeirista, a influência mineira e a policultura: tópicos da arquitetura rural de Itu [SP]
}

\author{
Maurício Maiolo Lopes \\ Pesquisador da Pontifícia Universidade Católica de Campinas, Faculdade de Arquitetura e Urbanismo. Campinas [SP], \\ Brasil.
}

Apresentado no 3ํㅗㄹ Seminário de Arquitetura Rural. Campinas [SP], Brasil, 2008.

\begin{abstract}
Resumo
O trabalho reúne alguns resultados de um inventário do Patrimônio Cultural da cidade de Itu [SP]. Apresentamos aqui o tópico referente à arquitetura rural, que, embora ainda não completo, apresenta nos levantamentos até então realizados algumas significativas considerações, das quais daremos destaque a dois aspectos: o primeiro é a relação entre a manutenção da tradição arquitetônica bandeirista e a influência mineira na segunda metade do século XVIII e meados do XIX; o segundo, é a constituição, no século XIX, de núcleos policultores. Diferente do oeste paulista onde foram constituídas novas unidades produtivas, voltadas particularmente à produção cafeeira, Itu se constitui caso singular por dois fatores: primeiro pela existência de uma expressiva variedade tipológica das casas sede, onde se destaca a manutenção do partido bandeirista com marcas da influência mineira verificadas no ciclo do "torna-viagem"; segundo, as fazendas não se constituem exclusivamente como unidades de produção monocultoras e sim como policultoras.
\end{abstract}

\section{Palavras-chave}

Arquitetura tradicional, arquitetura rural, patrimônio cultural.

\section{Among maintaining "bandeiristas" traditions, the mining influence and the polyculture: topics of the rural architecture from ltu [SP], Brazil}

\begin{abstract}
This work puts together some results of an inventory of Cultural Heritage of the city of Itu [SP], Brazil. Here the topic on rural architecture, which, although not yet complete, has so far conducted surveys in some major considerations, will focus on two aspects: first, the relationship between the maintenance of the "bandeirista" architectural tradition and the mining influence in second half of the 18th century and the mid-nineteenth; second is the constitution, in the 19th century, of the poly cultivators' core. Unlike of western of the State of São Paulo, where new plants were formed, particularly focused on coffee production, Itu is a singular case by two factors: first by a significant variety of housing types headquarters, which emphasizes the maintenance of the "bandeirista" party with traces of the mining influence experienced in the "torna-viagem" cycle; secondly, the farms aren't just taken as mono cultivators production units, they are poly cultivators.
\end{abstract}

\section{Keywords}

Traditional architecture, rural architecture, cultural heritage. 


\section{Introdução}

A cidade de Itu é das mais antigas de São Paulo. Fundada logo na primeira década do século XVII configurou-se durante longo tempo como a mais interiorizada vila de São Paulo, adquirindo, por isso, o título de "Boca do Sertão", pois até meados do século XVIII era ali o último entreposto comercial que abastecia áreas do CentroOeste como Mato Grosso. A partir de meados do século XVIII a produção açucareira trouxe grande prosperidade, fazendo com que Itu se tornasse a vila mais rica da província; em meados do século XIX a produção do café e do algodão também se tornaram atividades significativas. Essa história legou a Itu um expressivo número de fazendas, um representativo patrimônio cultural ainda não estudado. Nosso trabalho intenta chamar a atenção para a importância desse patrimônio, assim como indicar algumas de suas possíveis vertentes analíticas.

A primeira metade do século XVIII assinala uma profunda pobreza em São Paulo. Nesse período, a província sofreu com duas profundas alterações: o deslocamento de paulistas para regiões de exploração aurífera e a divisão da província, com a separação de Minas Gerais (1738), Goiás e Mato Grosso (1748). ${ }^{1}$

Entretanto, após a chegada do governador Morgado de Mateus, em 1764, a província entrou num profundo processo de transformação e enriquecimento ${ }^{2}$. É a partir desse momento que se inicia um novo período da história paulista, que Alfredo Ellis Júnior denominou "ciclo do açúcar paulista"3, ciclo esse que adentrou as primeiras décadas do século XIX e que desenvolveu bases econômico-estruturais para a cultura seguinte: o café.

A partir da chegada do novo governador, a província passou a merecer atenção especial e ser fundamental para o novo ciclo econômico da colônia brasileira, chamado de "Renascimento Agrícola", período de transição da economia mineral para a economia cafeeira. Nesse momento, uma desarticulação da produção açucareira antilhana ampliou os mercados mundiais abrindo um espaço para o açúcar da colônia portuguesa da América.

Segundo Maria Thereza Petrone, a vila de Itu se transformou nesse período, na principal produtora do açúcar paulista, pois "em Itu estava concentrada a maior parte da indústria açucareira". A prosperidade açucareira fez com que Itu se transformasse num dos mais importantes centros da riqueza paulista. Essas transformações fizeram com que a vila passasse a ser um dos principais pólos da cultura e da arte na província de São Paulo. Como relata Octávio Ianni, nesse período

\footnotetext{
${ }^{1}$ PRADO JÚNIOR, Caio. Formação do Brasil Contemporâneo. 4. Ed. São Paulo, Brasiliense, 1953.

2 PETRONE, Maria Thereza Schorer. A Lavoura Canavieira em São Paulo. São Paulo: Difusão Europeia do livro, 1968; BELLOTO, Heloísa Liberalli. Autoridade e Conflito no Brasil Colonial: o Governo do Morgado de Mateus em São Paulo. São Paulo, Secretaria do Estado e da Cultura, 1979.

${ }^{3}$ JÙNIOR, Alfredo Ellis. Raça de Gigantes. São Paulo, Novíssima Editora, 1926.

${ }^{4}$ PETRONE, Maria Thereza Schorer. Op. cit. p.43.
} 
[...] as igrejas se fizeram sólidas e imponentes. A música sacra se fez cultivada e solene. A pintura ganhou telas pintadas no lugar, nas quais as cenas da vida de Jesus predominam sobre qualquer outro tema religioso". Itu se tornou "o maior centro produtor de açúcar da Capitania e daí ser considerada a vila mais próspera, populosa e rica; e ltu se tornou o centro comercial e bancário das vilas vizinhas (IANNI, 1998, p.25-26)

Para o professor Francisco Nardy Filho, que pesquisou profundamente a história de Itu, o açúcar influenciou diretamente algumas transformações. Segundo ele

[...] a prosperidade do açúcar foi revelando seus frutos materiais e espirituais. A igreja de Nossa Senhora do Carmo foi construída entre os anos de 1777 e 1779, já em 1780 foi inaugurada a Igreja Matriz de Nossa Senhora da Candelária, em 1802 foi a vez da Igreja da Venerável Ordem Terceira de São Francisco, no ano de 1806, a Capela e o Hospital do Nosso Senhor do Horto, em 1820 inaugurou-se a Igreja de Nossa Senhora do Patrocínio e, em 1824 foi inaugurada a Igreja de Nossa Senhora das Mercês (NARDY, 1928, p.20-21) ${ }^{6}$.

Não só a arquitetura religiosa colheu os frutos dos canaviais. Se nas áreas urbanas constituíram-se os negócios comerciais e as atividades religiosas, nas áreas rurais, além da produção agrícola, organizou-se o complexo chamado Engenho. De acordo com o professor Jonas Soares de Sousa, pesquisador da cultura açucareira, nessa época em Itu o

[...] número de engenhos quase chegou à cifra de duas centenas. Do período restou um conjunto de testemunhos arquitetônicos, além de um conjunto de objetos, documentos textuais e iconográficos (SOUSA, Jornal da SAMUR, n.14, ano IV) ${ }^{7}$.

Quadro 1. Maiores produtores de açúcar da capitania de São Paulo (1799)

\begin{tabular}{|c|c|}
\hline Vilas & Arrobas (mil) \\
\hline Itu & 73,51 \\
\hline São Sebastião & 39,89 \\
\hline Porto Feliz & 30,67 \\
\hline Campinas & 16,88 \\
\hline Guaratinguetá & 9,09 \\
\hline
\end{tabular}

Fonte: Anais do Museu Paulista. São Paulo: Museu Paulista, 1961, Tomo 15. p.241, doc 20. Apud. Serrath, 2007.

Segundo Luís Saia, nesse período casas rurais "das antigas vilas, e estabelecimentos do planalto [...]" acabaram sendo influenciadas por um fenômeno que ele chamou de "torna viagem" de Minas Gerais para São Paulo. Ao retornar de Minas, esse paulista não é mais um aventureiro bandeirante, é "um pacato, um roceiro, um criador" e de Minas Gerais, carrega para cá

[...] outras tendências e outros costumes, bem assim outra arquitetura, outro tipo de residência, [...] com desenho, técnica e composição sensivelmente diversos

\footnotetext{
${ }^{5}$ IANNI, Octávio. Uma cidade antiga. Campinas: editora da UNICAMP, 1998. pp. 25-26.

${ }^{6}$ NARDY, Francisco - Filho. A Cidade de Itu. vol. I; São Paulo: Escola Profissionais Salesianas,1928, pp. 20-21.

${ }^{7}$ SOUSA, Jonas Soares de. Arquiteturas do açúcar em Itu. Em: Jornal da SAMUR, Ano IV, $n^{\circ} 14$
} 
daqueles que procediam da arquitetura paulista do ciclo anterior (SAIA, 1972, p.161-175).

Em Casas Bandeiristas: Nascimento e Reconhecimento da Arte em São Paulo (1976) o arquiteto Júlio Roberto Katinsky realizou um amplo estudo dos exemplares de tradição bandeirista em São Paulo. O professor Katinsky fez uma análise de 24 exemplares, dividindo-os em dois grupos: o primeiro, chamado de casas bandeiristas, propriamente ditas. São construções do ciclo bandeirista. Já as casas do período do açúcar, que

[...] apesar de apresentarem traços semelhantes às casas do primeiro lote, apresentam características próprias, denunciadoras de programa social diferente são tratadas como casas de "tradição bandeirista (KATINSKY, 1976).

Para essas casas, o pesquisador levantou, pelo menos, oito fundamentais características que as diferenciam das casas bandeiristas propriamente ditas. Ressaltamos aqui, que todas as casas arroladas em Itu neste estudo, se encaixam no grupo de "tradição bandeirista". 9

O arquiteto Carlos Lemos ressalta que na verdade não são paulistas que estão retornando de Minas Gerais, mas sim descendentes de paulistas, já de terceira ou quarta geração que devido a crise do ouro estão se transferindo para a próspera São Paulo. ${ }^{10} \mathrm{O}$ professor Lemos também realizou alguns pesquisas sobre a arquitetura bandeirista. Em Casa Paulista ele nos oferece as principais proposições do conjunto de suas pesquisas sobre a arquitetura civil paulista. Nesse trabalho ele dedica um capítulo às casas rurais do período do açúcar. Para ele o que começou a vigorar nesse período foi a coexistência de vários partidos arquitetônicos nas residências rurais que, por um lado, mantiveram-se utilizando soluções bandeiristas tradicionais e por outro lado, incorporaram as soluções trazidas pelas pessoas que de Minas Gerais vinham e/ou retornavam. ${ }^{11}$

[...] O partido bandeirista, isto é, aquele caracterizado pela integralidade assentada no chão e provida de "corredor" central separando a capela de quarto de hóspedes continuou a ser aceito com algumas alterações [...] na maior parte das vezes, mineiridades trazidas na bagagem de paulistas retornando à pátria, [esse é o partido do] "grupo ituano" [de casas]. ${ }^{12}$ (grifo nosso)

Em outro importante trabalho, o senhor Carlos Lemos também afirma que no final do século XVIII e início do XIX, havia duas arquiteturas rurais no planalto de São Paulo: uma de origem mineira e outra derivada da arquitetura antiga de São Paulo, da casa bandeirista. ${ }^{13}$

Entre as mais de três dezenas de fazendas históricas de Itu, um grupo de nove ainda mantém suas sedes bandeiristas sem alterações ou com intervenções que

\footnotetext{
${ }^{8}$ SAIA, Luís. Intermezzo Roceiro. Em: Morada Paulista. São Paulo, Perspectiva, 1972. pp.161-175.

${ }^{9}$ KATINSKY, Júlio Roberto. Casas Bandeiristas: Nascimento e reconhecimento da Arte em São Paulo. São Paulo, Instituto de Geografia,1976. pp.59-61

${ }^{10}$ LEMOS, Carlos. Casa Paulista: história das moradias anteriores ao ecletismo trazido pelo café. São Paulo, Editora da Universidade de São Paulo, 1999. p.128.

${ }_{11}^{11}$ LEMOS, Carlos. op. cit. pp.127-129.

${ }^{12}$ LEMOS, Carlos. op. cit., pp. 128.

${ }^{13}$ LEMOS, Carlos Alberto Cerqueira. Cozinhas, Etc; um estudo sobre as zonas de serviço da Casa Paulista. São Paulo, Perspectivas, 1978. pp.64-65.
} 
não modificaram significativamente sua originalidade. Nesse primeiro grupo estão as seguintes fazendas:
a) Fazenda Nossa Senhora da Ponte
b) Fazenda Nossa Senhora da Conceição
c) Fazenda Nossa Senhora do Rosário
d) Fazenda Campo Neto (Pirapitinguí)
e) Fazenda Jurumirim
f) Fazenda Capoava
g) Fazenda Pau D`Alho
h) Fazenda Vassoural
i) Chácara São João

No segundo grupo, encontram-se as casas que eram originalmente de tradição bandeirista e que sofreram modificações significativas ao longo do século XIX. Aqui se encontram pelo menos outros cinco casos:
a) Fazenda da Serra
b) Fazenda Paraíso
c) Fazenda Pirahy
d) Fazenda Sítio Grande
e) Fazenda Cana Verde

O período que se seguiu a meados oitocentismo anotou a introdução de novas culturas, sobretudo o café e o algodão; entretanto, o açúcar continuou a ser produzido e grande escala, de tal forma praticamente toda a segunda metade do século XIX assinalaria de forma significativa e paralela, a produção dessas três culturas.

A cultura do algodão em Itu foi notável antes mesmo da inauguração da fábrica de tecidos São Luiz (1869) e também antes da implantação da fazenda São Carlos (1862), uma fazenda modelo criada por Carlos Ildro da Silva e que, durante seu curto tempo de vida, serviu à reprodução de sementes a outras fazendas de Itu e região.

[...] Por intermédio da Sociedade Auxiliadora da Indústria Nacional recebeu este agricultor uma boa porção de sementes de algodoeiro 'Sea-Island', importadas diretamente dos Estados Unidos, e outra porção da variedade índica, cultivada na Província do Maranhão, provenientes de sementes importadas dos estados Unidos. Estas sementes foram plantadas em Novembro e dezembro, respectivamente, do ano de 1862. Em Julho de 1863 estava Carlos Ildro da Silva em pleno trabalho de colheita. As sementes dessa primeira cultura do algodão herbáceo, segundo comunicação daquele fazendeiro, foram gratuitamente distribuídas entre 133 agricultores de dezesseis municípios da Província. Concomitantemente às primeiras sementeiras de 1862, outras se faziam em Itu, por alguns lavradores do município, os quais haviam conseguido sementes por intermédio de amigos (CANABRAVA, 1951, p.50-52) ${ }^{14}$.

\footnotetext{
${ }^{14}$ CANABRAVA, Alice Piffer. O desenvolvimento da cultura do algodão na Província de São Paulo(1861-75) São Paulo, 1951.
} 
Quadro 2. Produção ituana em meados do século XIX

\begin{tabular}{|c|c|c|c|c|}
\hline & 1854 & 1866 & 1868 & 1886 \\
\hline algodão & - & 46740 arrobas & - & - \\
\hline açúcar & - & 49900 arrobas & 40000 arrobas & - \\
\hline café & 16702 arrobas & - & 20000 arrobas & 46667 arrobas \\
\hline
\end{tabular}

Fonte: Canabrava, 1951, p.61; lanni, 1986, p.50.

Em alguns dos testemunhos arquitetônicos, vemos que ao lado do cultivo do algodão funcionava a fabricação do açúcar, a produção cafeeira, a criação de suínos e de gado. Nesse período, a tradição bandeirista foi substituída por uma expressiva variedade tipológica em suas casas sede.

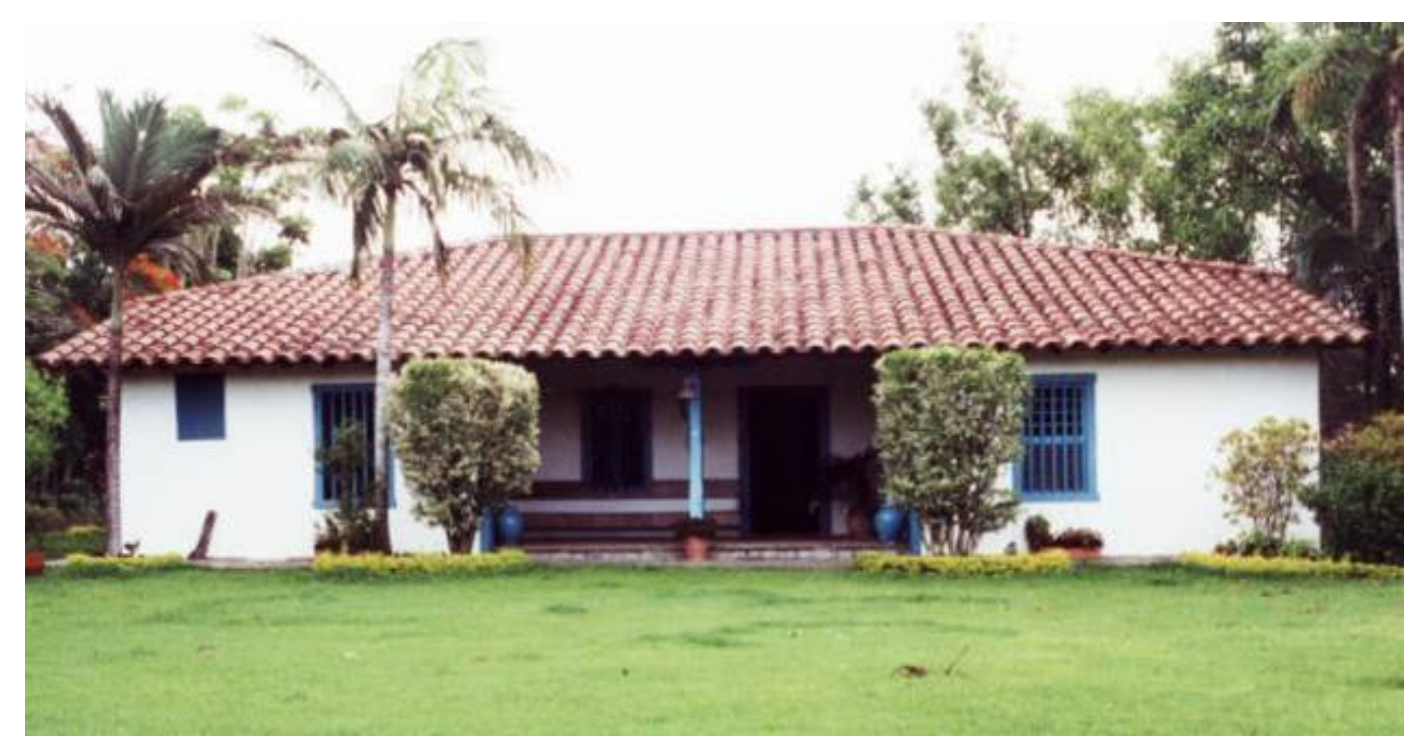

Figura 1. Sede da Fazenda Nossa Senhora da Conceição: Entre as casas de tradição bandeirista, a mais bem conservada.

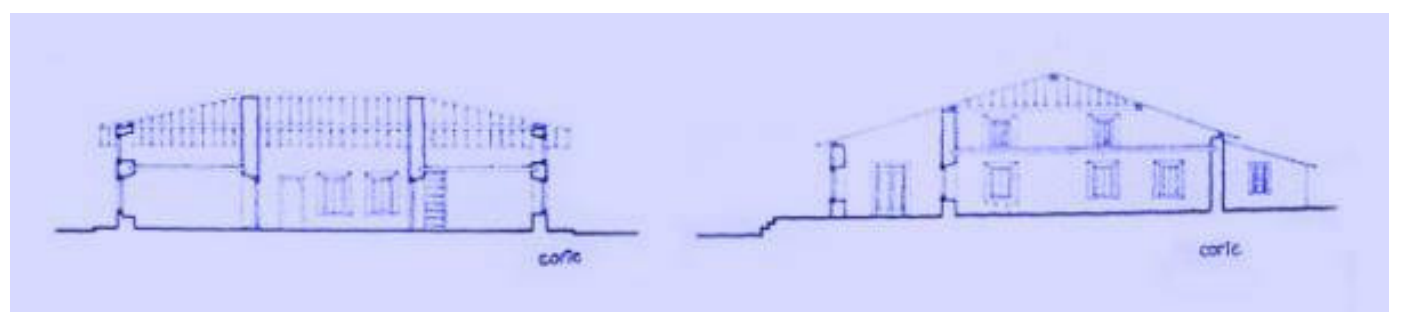

Figura 2. Sede da Fazenda Nossa Senhora da Conceição: Cortes. 


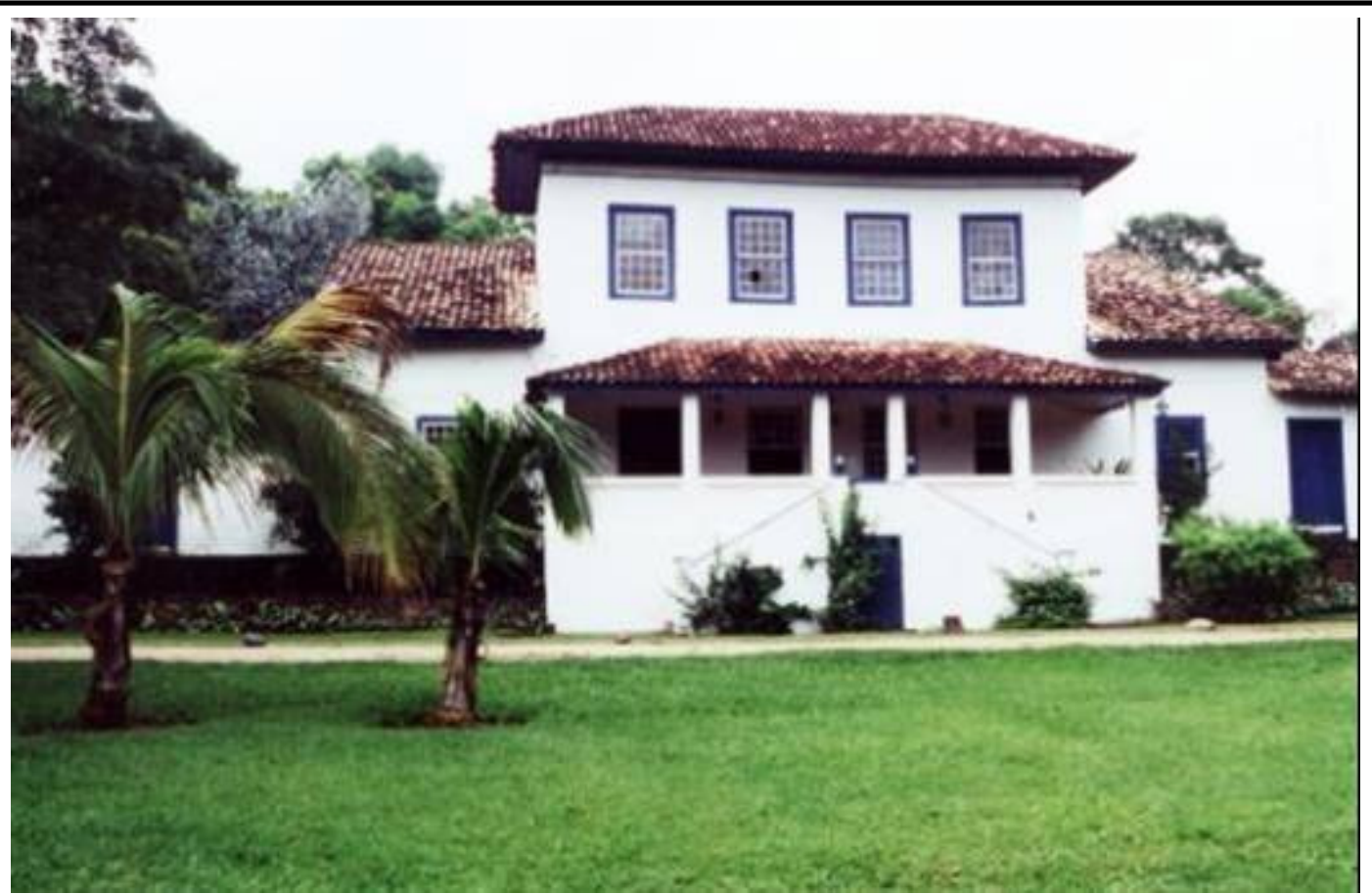

Figura 3. Sede da Fazenda Pirahy: Uma casa bandeirista que ganhou segundo pavimento em meados do século XIX. Técnicas construtivas e o segundo pavimento são indícios de influência da arquitetura colonial de Minas Gerais.
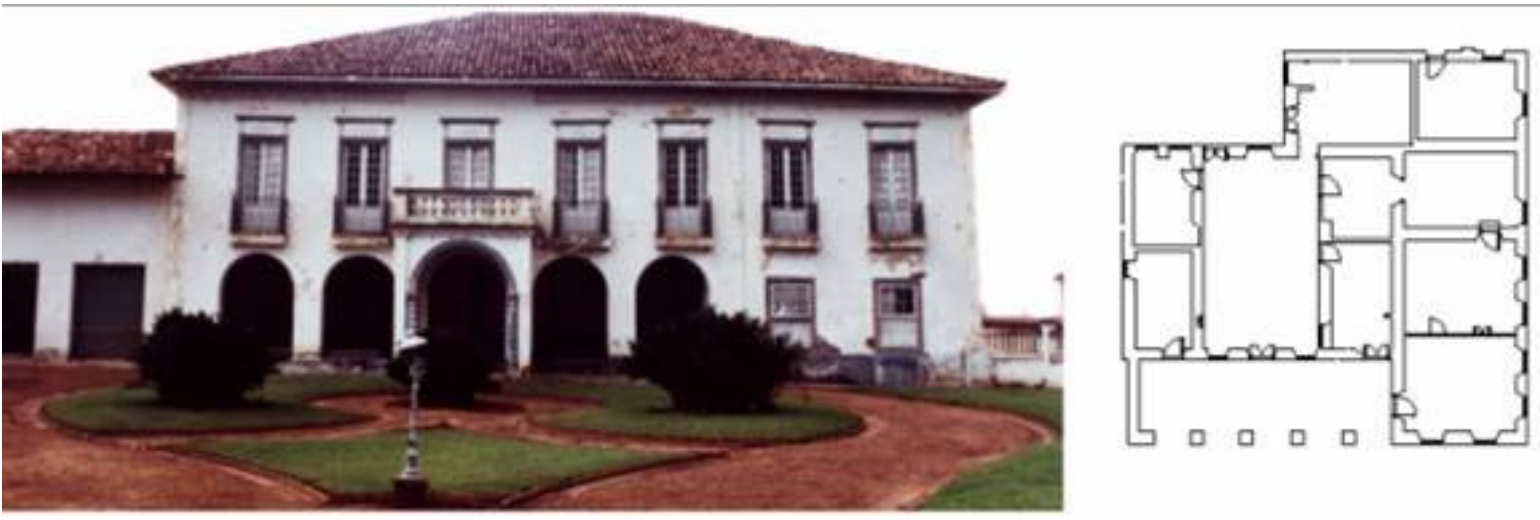

Figura 4. Sede da Fazenda Paraíso: sua planta baixa denuncia que originalmente foi uma casa bandeirista; em meados do século XIX o edifício ganhou acréscimos na planta baixa, além da construção de um segundo pavimento. 


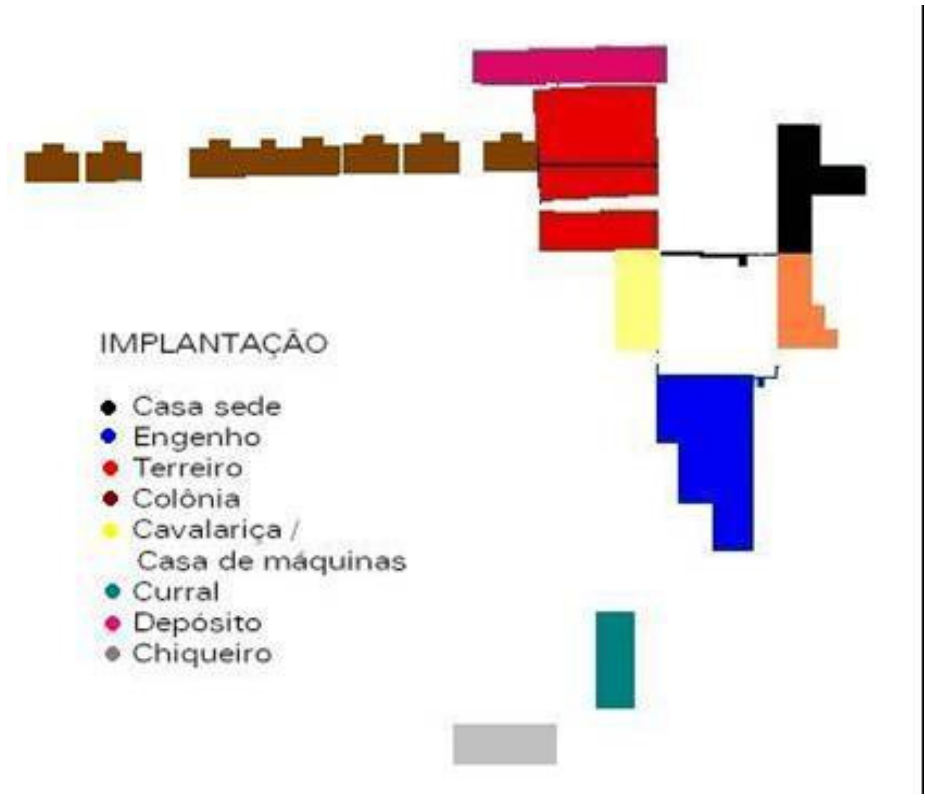

Figura 5. Fazenda Vassoural: A reforma realizada no final do século XIX transformou o antigo Engenho em uma fazenda policultora.

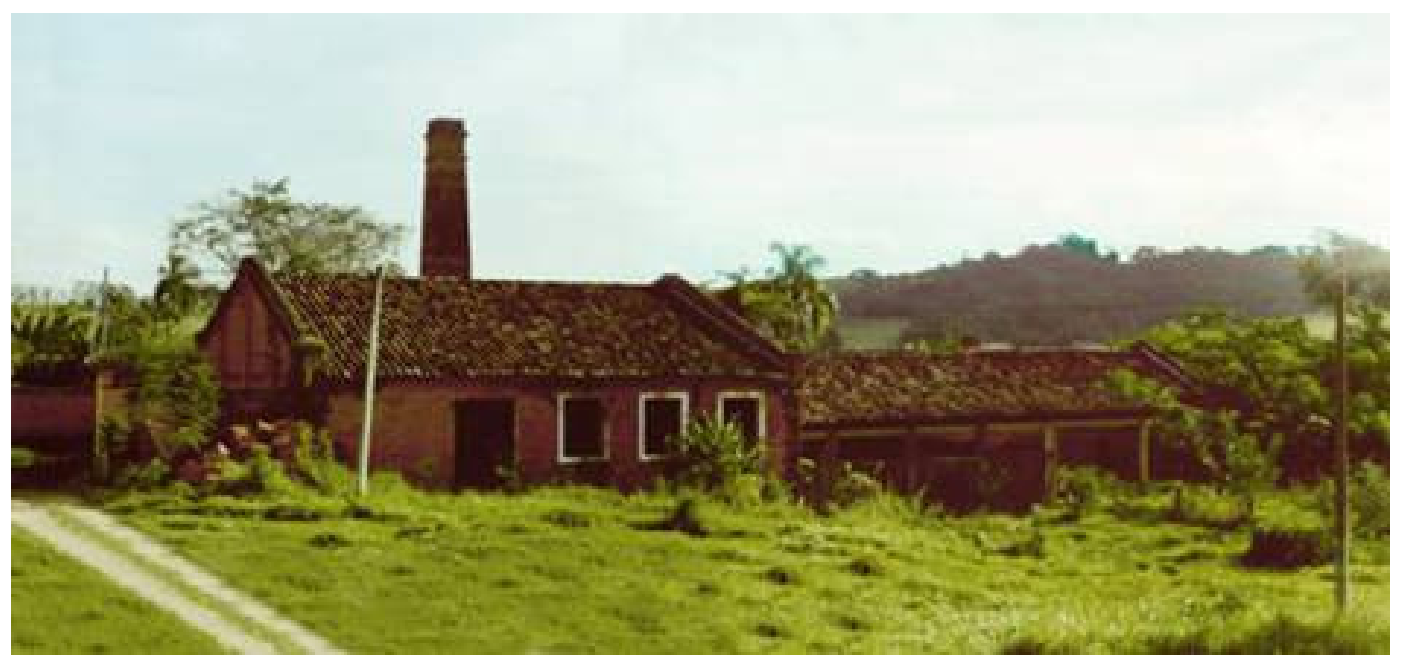

Figura 6. Fazenda Vassoural: Engenho construído em fins do século XIX.

\section{Referências}

BELLOTO, Heloísa Liberalli. Autoridade e Conflito no Brasil Colonial: o Governo do Morgado de Mateus em São Paulo. São Paulo, Secretaria do Estado e da Cultura, 1979.

CANABRAVA, Alice Piffer. O desenvolvimento da cultura do algodão na Província de São Paulo (1861-75). São Paulo, 1951

IANNI, Octávio. Uma cidade antiga. Campinas: editora da UNICAMP, 1998. pp. 25-26.

JÙNIOR, Alfredo Ellis. Raça de Gigantes. São Paulo, Novíssima Editora, 1926.

LOPES, M. M. Entre a manutenção da tradição bandeirista, a influência mineira e a policultura: tópicos da arquitetura rural de Itu [SP]. Labor \& Engenho, Campinas [Brasil], v.1, n.2, p.32-40, 2008. Disponível em: <www.conpadre.org>e $<w w w$ labore.fec.unicamp.br>. 
KATINSKY, Júlio Roberto. Casas Bandeiristas: Nascimento e reconhecimento da Arte em São Paulo. São Paulo, Instituto de Geografia,1976

LEMOS, Carlos Alberto Cerqueira. Cozinhas, Etc; um estudo sobre as zonas de serviço da Casa Paulista. São Paulo, Perspectivas, 1978.

. Casa Paulista: história das moradias anteriores ao ecletismo trazido pelo café. São Paulo, Editora da Universidade de São Paulo, 1999.

MIRANDA, Alcides da Rocha e CZAJKOWSKI, Jorge. Fazendas: Solares da Região Cafeeira do Brasil Imperial. Rio de Janeiro, 1995.

NARDY, Francisco - Filho. A Cidade de Itu. vol. I; São Paulo: Escola Profissionais Salesianas,1928.

PETRONE, Maria Thereza Schorer. A Lavoura Canavieira em São Paulo. São Paulo: Difusão Europeia do livro, 1968.

PRADO JÚNIOR, Caio. Formação do Brasil Contemporâneo. 4. Ed. São Paulo, Brasiliense, 1953.

SAIA, Luís. Morada Paulista. São Paulo, Perspectiva, 1972.

SERRATH, Pablo Oller Mont. Produção do açúcar na capitania de São Paulo (1793-1802). Em: Anais do II Seminário de História do Açúcar: Trabalho, população e cotidiano; Museu Paulista, São Paulo, 2007

SOUSA, Jonas Soares de. Arquiteturas do açúcar em Itu. Em: Jornal da SAMUR, Ano IV, nº 14. 